\title{
AVALIAÇÃO DA \\ CONSCIENTIZAÇÃO SOBRE A DESTINAÇÃO DOS RESÍDUOS SÓLIDOS URBANOS NAS \\ UNIVERSIDADES EM BELÉM (PA)
}

Layna Marcia de Jesus Amaral Lima ${ }^{1}$

Mônica Trindade Abreu²

Resumo: Segundo o Ministério de Meio Ambiente (MMA), os países, em geral, mostram dados preocupantes em relação à geração de resíduos sólidos urbanos. O objetivo deste trabalho foi buscar levantar dados sobre a destinação dos resíduos sólidos em universidades e residências, além de avaliar o conhecimento dos discentes relacionados ao destino desses resíduos na Região Metropolitana de Belém (RMB), visto que, a reciclagem impacta na sustentabilidade, qualidade de vida e socialmente. Os resultados foram relevantes, já que representam as principais dificuldades da população com relação a destinação dos resíduos sólidos, demonstrando a necessidade de muito envolvimento institucional, no tocante à Educação Ambiental.

Palavras-chave: Coleta seletiva; Sustentabilidade; Educação Ambiental.

Abstract: According to the Ministry of environment (MMA), countries generally show worrying data regarding the generation of municipal solid waste. The objective of this work was to collect data on the disposal of solid waste in universities and residences, in addition to evaluating the knowledge of students related to the destination of these residues in the Metropolitan Region of Belém (RMB, PA, Brazil), since recycling impacts sustainability, quality of life and socially. The results were relevant, since they represent the main difficulties of the population in relation to the disposal of solid waste, demonstrating the need for much institutional involvement in Environmental Education.

Keywords: Selective collect; Sustainability; Environment education.

2Universidade Federal Rural da Amazônia (UFRA). E-mail: monica.gusmao@ufra.edu.br. Link para o Lattes: http://lattes.cnpq.br/4409997048754420 


\section{Introdução}

Segundo o Ministério de Meio Ambiente (MMA) através da Gestão Integrada de Resíduos Sólidos na Amazônia, os países, em geral, mostram dados preocupantes em relação à geração de resíduos sólidos urbanos. A questão ambiental está se tornando um tema relevante que precisa ser discutido em toda extensão da sociedade civil, portanto, não há dúvida de que o acúmulo de lixo nas cidades é um dos principais problemas ambientais da atualidade (BARBIERI, 2017). Há algumas décadas, não havia preocupação com a sustentabilidade do planeta. Segundo o autor, atualmente, a tecnologia e os estudos acadêmicos apontam inúmeras possibilidades de progredir sem prejudicar o meio ambiente, basta que todo empreendimento se preocupe um pouco mais com a natureza e a vida no planeta.

Conforme o IBAM - Instituto Brasileiro de Administração Municipal o crescimento da população urbana e dos resíduos sólidos começa a atrair a atenção das pessoas, e são necessárias medidas para manuseá-los e gerenciá-los adequadamente, evitando problemas ambientais, de saúde e sociais. Assim, os resíduos mais comuns podem ser caracterizados pela composição domiciliar, hospitalar e industrial, sendo que os resíduos sólidos domiciliares se apresentam diversificados qualitativamente e quantitativamente (DE SOUZA et al., 2020). De acordo com os dados do Censo Demográfico de 2010, $90 \%$ dos domicílios urbanos no Brasil possuíam coleta direta de lixo e $72 \%$ dos domicílios localizados na área rural não dispunham de nenhum tipo de coleta de resíduos (IBGE, 2010). Cabe destacar a dificuldade, nos grandes centros, de locais para disposição do lixo, devendo então serem implementadas as medidas de redução, reutilização e reciclagem.

De acordo com a Constituição Federal, o gerenciamento do manejo de resíduos sólidos é de competência do poder público local, ainda que possa ser exercido por empresas particulares por meio de concessão pública, a Região Norte se destaca como a de maior percentual de prestadoras de serviço de natureza pública (mais de $80 \%$ ). Segundo dados da Pesquisa Nacional de Saneamento Básico (PNSB) do Instituto Brasileiro de Geografia e Estatística (IBGE), em 2008 a disposição final ambientalmente correta era realidade de apenas 1.092 dos 5564 municípios brasileiros.

Conforme o PNSB (2008), o volume de resíduos sólidos domiciliares e/ou públicos coletados no Brasil foi de 183.488 toneladas ao dia, em comparação a pesquisa em 2000 mostra que houve um aumento de 58.207 toneladas ao dia. A quantidade de lixo produzida diariamente por um brasileiro é estimada em aproximadamente $1 \mathrm{~kg}$, sendo fruto do homem em seu consumo desenfreado por matérias-primas ou industrializado, sem uma destinação final adequada (MOLINARI, 2017). Tal aumento merece a atenção das autoridades municipais, acompanhado de estratégias de destinação final, pois a destinação inadequada pode ter impactos sociais, ambientais e econômicos com prejuízos para a população e o meio ambiente. 
De acordo com o MMA, a lei no 12.305 / 10, que instituiu a Política Nacional de Resíduos Sólidos (PNRS), contém importantes ferramentas que permitem ao país avançar no enfrentamento das principais questões ambientais, sociais e econômicas decorrentes do manejo inadequado dos resíduos sólidos. Tal legislação consta a eliminação dos "lixões" até 2014 e substituição por aterro sanitário, coleta seletiva, logística reversa, participação da população, incluindo o trabalho de cooperativas de catadores com viés inclusivo e social, tanto na Logística Reversa quando na Coleta Seletiva. Porém, a data se estendeu para 2012 a 2018, dependendo do tamanho da população municipal, pois muitos municípios estão com dificuldades para cumprir o prazo, de acordo com o Projeto de Lei 2289/15.

Salienta-se que, o descarte inadequado foi inicialmente proibido em 1954, pela Lei 2.312 de 3 de setembro pelo Código Nacional da Saúde. Tal proibição foi reforçada em 1981 pela Política Nacional de Meio Ambiente, posteriormente, em 2010, pela Política Nacional dos Resíduos Sólidos.

Portanto, a separação e reciclagem de resíduos são as melhores opções para reduzir a quantidade de resíduos, que podem ser descartados em aterros ou incinerados em condições controladas. Em relação à coleta seletiva, o Brasil apresenta melhorias em relação aos últimos anos, cerca de $60 \%$ dos municípios já registraram algum projeto de coleta seletiva, embora esses dados sejam muito importantes, deve-se destacar que esses programas muitas vezes não cobrem toda a população e a eficiência das comunidades atendidas nem sempre é satisfatória (MARQUES, 2017).

Dessa forma, é essencial que os moradores tenham consciência de sua importância na gestão adequada dos resíduos sólidos, pois também é produtora desses resíduos. Construindo valores sociais, habilidades, atitudes e competências voltadas para a conservação do meio ambiente, qualidade de vida e sustentabilidade, e ainda, como disseminadora de conhecimento e formadora de opinião pública, as Universidades devem fazer o discurso de uma maneira simples e prática para resolver problemas de resíduos sólidos por meio de participação, reflexão, compromisso pessoal, mudança de hábitos e de atitudes para proteger a natureza.

O objetivo deste trabalho foi levantar dados sobre a destinação dos resíduos sólidos na universidade e residência, salientar sobre os problemas enfrentados na separação, além de avaliar os conhecimentos dos discentes relacionados ao destino do resíduo sólido na Região Metropolitana de Belém. Tal estudo contribui para um descarte de resíduo mais consciente, induz ao reaproveitamento, e dessa forma, faz uma análise sobre o desperdício exacerbado e inconsciente. 


\section{Material e métodos}

Para este trabalho foi utilizado o método de cunho bibliográfico, buscando nas literaturas correlatas informações disponíveis e relevantes sobre a temática abordada, procurando discutir os critérios de inclusão adotados do material analisado envolvem: legislação sobre resíduos sólidos no Brasil, problemas ambientais, gestão ambiental e consciência do descarte dos resíduos sólidos. E também obtenção de dados quantitativos sobre os objetivos gerais da pesquisa.

Também buscou-se entender os principais problemas sobre coleta seletiva na região, além disso, o tema foi respaldado na legislação vigente. As fontes dos estudos analisadas foram: pesquisa bibliográfica sobre manejo de resíduos sólidos de notícias/pesquisas, periódicos, dissertações, legislação e informativos de órgãos estatais e federais.

Dessa forma, foi definido um público-alvo, sendo os alunos de universidades localizadas na Região Metropolitana de Belém (RMB) (Figura 1), no Estado do Pará, a fim de alcançar resultados que detivessem respostas sobre a conscientização e levantamento da destinação dos resíduos após o uso na universidade e residência dos entrevistados. Além disso, foram analisados os dados especificamente dos discentes de engenharia ambiental para avaliar os conhecimentos básicos sobre a destinação dos resíduos sólidos urbanos na Região Metropolitana de Belém.

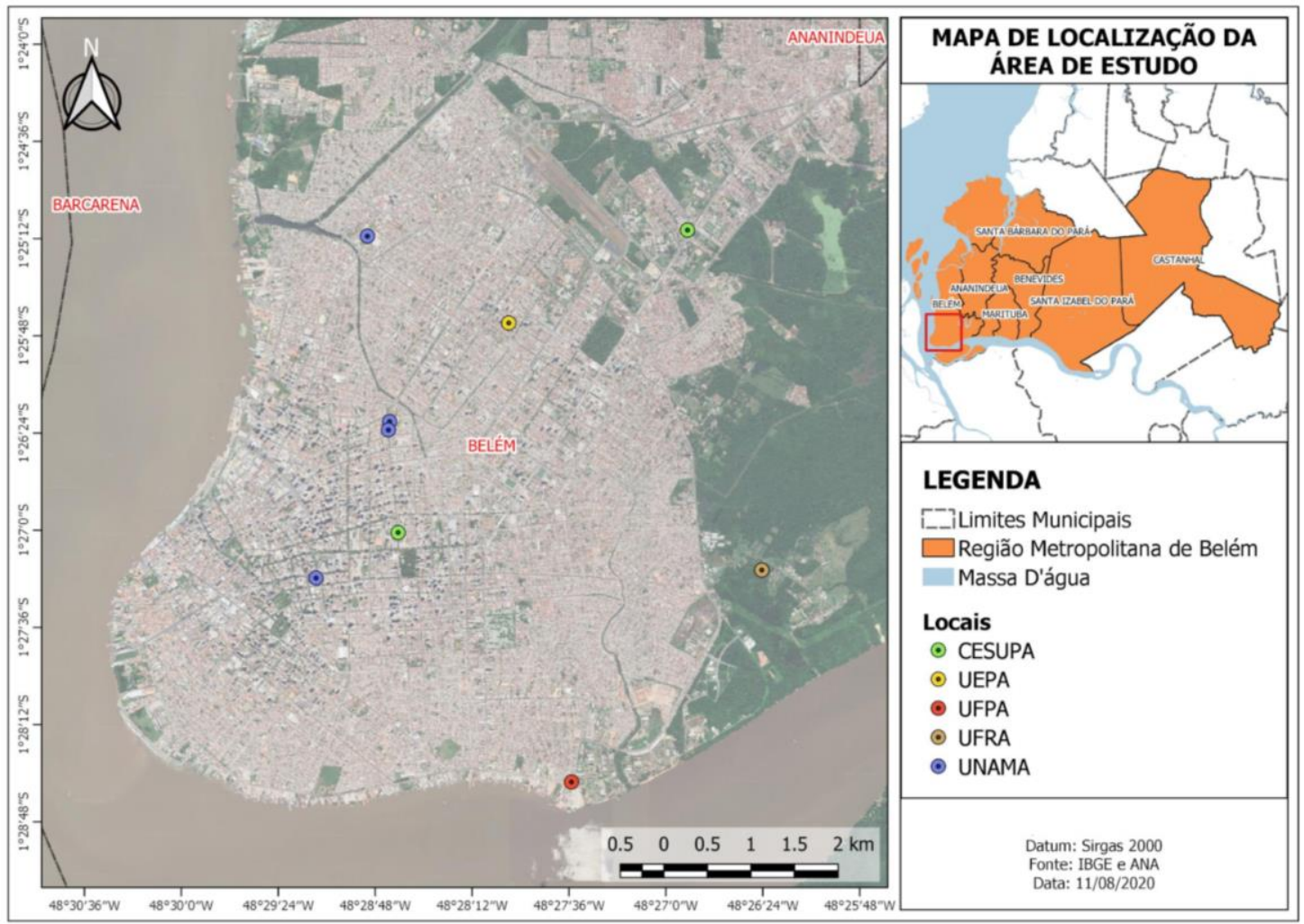

Figura 1: Localização das universidades onde o questionário foi aplicado.

Fonte: Os autores (2020). 
Foi elaborado um questionário através da plataforma Google Forms nos meses de julho e agosto de 2020, aplicados a alunos de 16 cursos em 5 universidades diferentes, como demonstrado no mapa da Figura 1. As perguntas abordaram o tema dos resíduos sólidos quanto a destinação, dificuldades de separação e destinação, reconhecimento da destinação desses resíduos no município e pontos de coleta acessíveis. Foi utilizado o software Microsoft Excel 2016 para analisar os dados e gerar os gráficos.

\section{Resultados e discussão}

As respostas ao questionário aplicado aos discentes das universidades da RMB, foram importantes fontes para compreender quais os entendimentos dos entrevistados sobre o destino do resíduo, quais as alternativas que encontram diante do crescente volume de lixo produzido pela sociedade e sua contribuição para a preservação do meio ambiente.

A Política Nacional de Resíduos Sólidos, Lei n 12.305/2010, traz a classificação para os resíduos sólidos quanto à origem e periculosidade, assim apresentados:

a) resíduos domiciliares: os originários de atividades domésticas em residências urbanas;

b) resíduos de limpeza urbana: os originários da varrição, limpeza de logradouros e vias públicas e outros serviços de limpeza urbana;

c) resíduos sólidos urbanos;

d) resíduos de estabelecimentos comerciais e prestadores de serviços;

e) resíduos dos serviços públicos de saneamento básico;

f) resíduos industriais;

No Brasil, embora exista em muitas cidades, a reciclagem ainda é um processo inicial, com muito pouco material envolvido, o foco é usado em latas de alumínio, enquanto outros materiais continuam a apresentar baixas taxas de reciclagem (DE CARVALHO, 2016). Segundo o autor, um dos principais problemas da reciclagem é, em sua maior parte, resultado da atividade de catadores e não consequência de um comprometimento mais profundo e generalizado da população e das autoridades com o processo de separação e coleta seletiva do lixo. Assim, mostra que deve haver o comprometimento da população aliada ao trabalho dos catadores. A Figura 2 mostra a porcentagem de entrevistados em cada universidade localizada na Região Metropolitana de Belém. 


\section{UNIVERSIDADE}

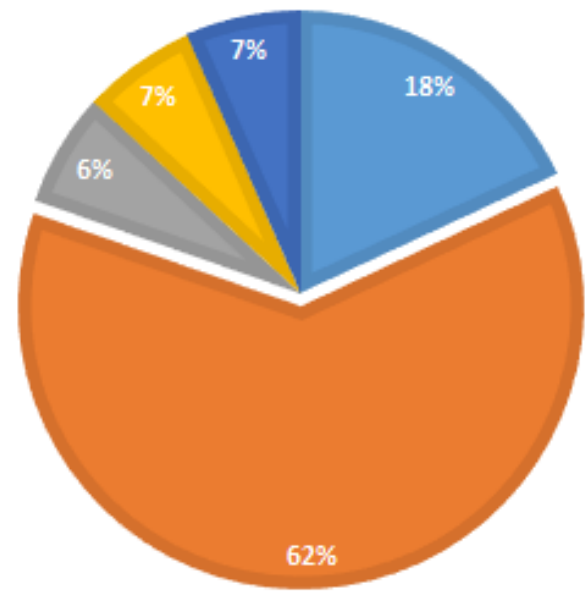

- Universi dade Federal do Pará - UFPA

- Universi dade Federal Rural da Amazônia

- UFRA

- Universidade da Amazônia - UNAMA

n Universidade Estadual do Pará - UEPA

- Cesupa

Figura 2: Porcentagem dos entrevistados nas universidades.

Fonte: Os autores (2020).

Os entrevistados, tinham idades entre 17 e 48 anos, sendo $18 \%$ com 19 anos, $15 \%$ com 20 anos, 3\% com 21 anos e 15\% com 22 anos, ou seja, $51 \%$ dos entrevistados tinham entre 19 a 22 anos. Cabe destacar que a maioria dos entrevistados foram mulheres (66\%). Os alunos entrevistados eram oriundos de cinco universidades da Região Metropolitana de Belém, sendo que a pesquisa abrangeu 16 cursos distintos (Figura 3).

\section{CURSOS}

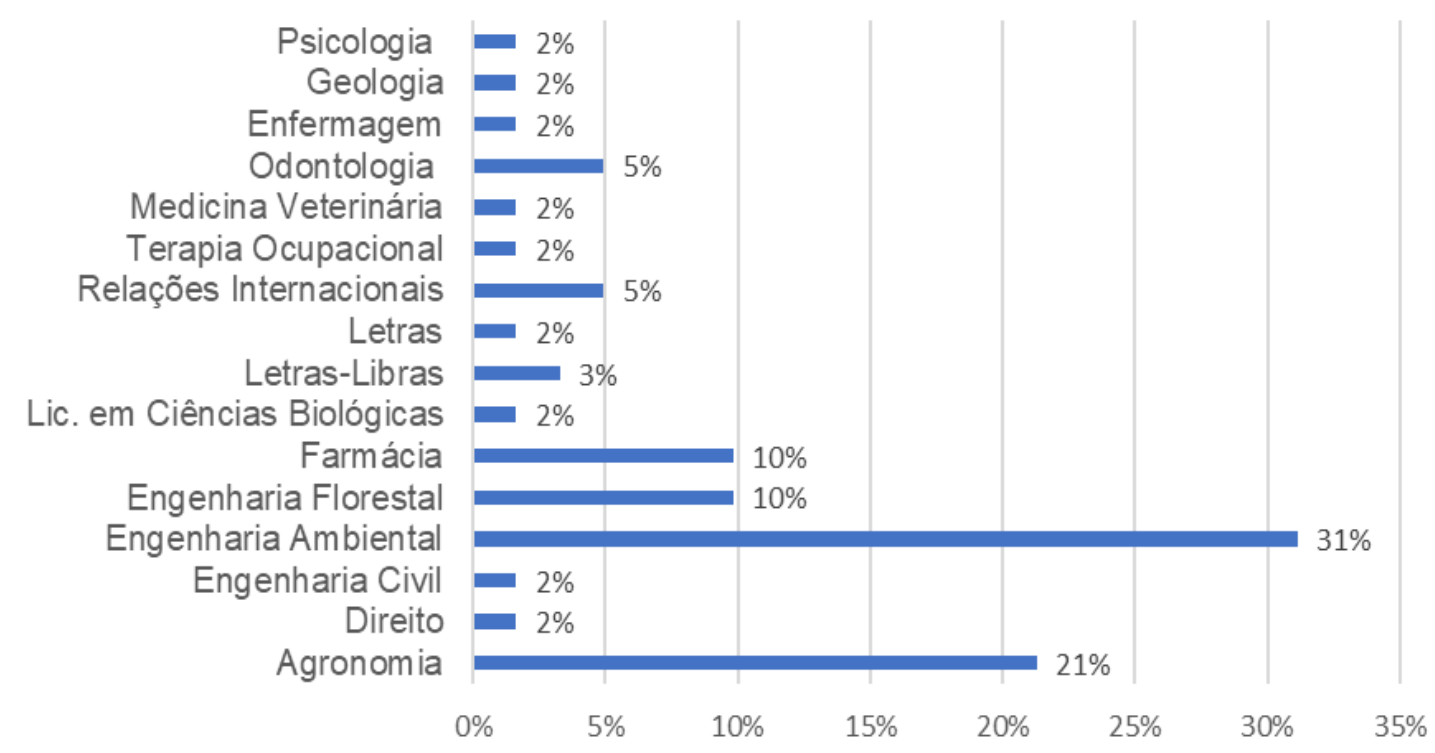

Figura 3: Porcentagem dos cursos dos entrevistados.

Fonte: Os autores (2020). 
Quando os discentes foram abordados sobre o que fazem com o lixo produzido na universidade, nenhum dos entrevistados afirmou que joga lixo em qualquer lugar, porém $20 \%$ alegam que joga o lixo em lixeiras comuns sem destinação adequada, cerca de $38 \%$ afirmam que procura as lixeiras da coleta seletiva para o descarte e $42 \%$ guarda e procura uma lixeira para jogar, independentemente de seleção. Segundo Rodrigues (2017), muitas pessoas acreditam que não jogar lixo no chão ou em lugares inadequados representa uma importante contribuição na preservação da natureza. Porém, de acordo Souza (2014), constatou-se que apenas $8 \%$ de tais ações são responsáveis pela diminuição no consumo de produtos industrializados como forma de reduzir o lixo gerado.

Salienta-se que, de acordo com os dados recebidos, as principais dificuldades encontradas pelos discentes sobre a separação dos materiais com potencial reciclável são a mudança de hábitos e conscientização, falta de recipientes adequados e de conhecimento sobre os locais para coleta. Por conseguinte, os empecilhos encontrados para destinar os resíduos são principalmente a falta de conhecimento dos pontos de coleta.

É importante salientar que, as universidades são grandes geradoras de resíduos sólidos domésticos, químicos, de serviços de saúde, industriais, em quantidades e características variadas. Nos órgãos e entidades da administração pública federal do Brasil a publicação do Decreto no 5.940, em 2006, pelo Governo Federal, instituiu a separação, dos resíduos recicláveis descartados e a sua destinação às associações e cooperativas dos catadores de materiais recicláveis.

Posteriormente foi questionado se havia a separação de resíduos sólidos na residência dos entrevistados e em apenas 33\% das casas há algum tipo de divisão dos materiais recicláveis. Apesar do crescimento da quantidade de municípios brasileiros que adotam a coleta seletiva, a massa total recuperada por este sistema de segregação implica em menos de $2 \%$ do total dos resíduos sólidos urbanos coletados (BRASIL - SNIS, 2018). Percebendo-se que a coleta seletiva precisa ser expandida, assim como a população precisa de maiores informações.

Segundo Mol et al. (2020), a implantação da coleta seletiva nas residências deve ser aplicada de forma gradativa e contínua, a fim da população incorporar à rotina. Sendo assim, a Educação Ambiental é importante para conscientizar e informar a comunidade e para que reconheça a importância da reciclagem atualmente. $O$ descarte inadequado dos materiais com potencial reciclável é uma das principais reclamações dos catadores, pois assim enfrentam grande dificuldade durante a separação dos resíduos e isto ocorre pela falta de orientação da população e/ou dos estabelecimentos quanto à destinação correta dos resíduos. Tais problemas representam riscos para os trabalhadores da cooperativa durante a triagem por estarem em contato direto com os resíduos e expostos a materiais perfurantes e de caráter infeccioso. 
Cerca de $89 \%$ dos entrevistados afirmam não haver pontos de coleta próximo das residências, porém de acordo com a Secretaria Municipal de Saneamento (SESAN), em 2019, havia 30 ecopontos distribuídos na capital e distritos para separação de resíduos recicláveis. Além de possuir cooperativas na RMB como Cooperativa dos Catadores de Materiais Recicláveis (CONCAVES), Cooperativa de Catadores de Materiais Recicláveis Visão Pioneira de Icoaraci (COCAVIP), Cooperativa de Catadores de Materiais Recicláveis Filhos do Sol (CCMRFS), Cooperativa de Trabalho dos Profissionais em Consultoria Empresarial e Cooperativista (AMAZON FOCUS), Cooperativa de Trabalho dos Profissionais de Saúde da Amazônia (AMAZOMCOOP).

Segundo os entrevistados, $61 \%$ descartam o papel em lixeira comum, sem se preocupar em dar um descarte adequado, enquanto, $31 \%$ descartam seletivamente em uma lixeira comum e apenas $8 \%$ reutilizam. Porém, o papel usado é um material com grande possibilidade de reaproveitamento e para cada tonelada de papel reciclado são poupadas aproximadamente vinte árvores.

Visando tal problema apontado na pesquisa, destaca-se a importância da reciclagem na indústria de papel e celulose como forma de minimizar os impactos ao meio ambiente, Santos (2017) relata que a reciclagem de papel reduz energia para a produção de papel e celulose, redução na poluição do ar, redução na poluição da água e redução no uso de água.

Enquanto $54 \%$ dos entrevistados descartam as latinhas de alumínio em lixeiras comuns, $44 \%$ descartam em lixeiras recicláveis e somente $2 \%$ reutilizam o material. Apesar do alumínio ser um metal durável, possuindo enorme potencial de reciclagem (CORREIA et al., 2018). Segundo o autor, a destinação do alumínio pode causar um grande impacto ao meio ambiente, porém, apresenta inúmeras oportunidades de reciclagem ou reuso, trazendo resultados positivos. Porém, há dificuldades da reciclagem desse material pela falta da coleta seletiva, pois se não há separação, gera dificuldades no processo e deprecia o produto.

De acordo com Marques (2017) ao mensurar a participação da população, verificou que a participação social tem sido uma das principais dificuldades no planejamento da implantação de programas de coleta seletiva. Isto porque tal ação depende do perfil socioeconômico e cultural, acrescida de adequação do projeto à realidade local, da regularidade no funcionamento da logística implantada e da eficiência da estratégia de marketing para a sensibilização e participação da população.

Segundo Gonçalves (2018), o consumo passou a ser um hábito a fim de satisfazer necessidades supérfluas, desta forma a sociedade passou a buscar maneiras de conciliar o progresso econômico e a preservação dos recursos ambientais. Para isso, a relação de consumo exacerbada deve ser urgentemente freada e substituída por uma relação mais consciente onde seja 
priorizado a relação do consumo e do meio ambiente, cerca de $59 \%$ dos entrevistados afirmam se preocupar em escolher produtos que agridam menos o meio ambiente. Diante disso, é possível inferir que há uma preocupação significativa com o meio ambiente, buscando o desenvolvimento sustentável.

\section{Destinação dos resíduos na Região Metropolitana de Belém (RMB)}

De acordo com a Política Nacional de Resíduos Sólidos (PNRS), os resíduos devem ser dispostos em aterro sanitário a fim de minimizar danos e riscos ao meio ambiente e à saúde pública. Assim, a destinação dos resíduos em espaços inadequados para o tratamento final é um reflexo da falta de implementação de políticas públicas, com participação das gestões municipais e estaduais (SOARES, 2017), podendo ser reaproveitados os gases e o chorume liberados. Apenas $34 \%$ dos discente responderam saber o destino dos resíduos da $\mathrm{RMB}$, porém desses, $29 \%$ ainda afirmam que o destino é o antigo aterro do Aurá, conhecido como "Lixão do Aurá" (Figura 4), desativado em julho de 2015 e que operou durante 20 anos, recebendo por dia quase duas mil toneladas de resíduos dos municípios de Belém, Ananindeua, Marituba, Benevides e Santa Bárbara, localizados no estado do Pará.

\section{DESTINO DOS RESÍDUOS EM BELÉM}

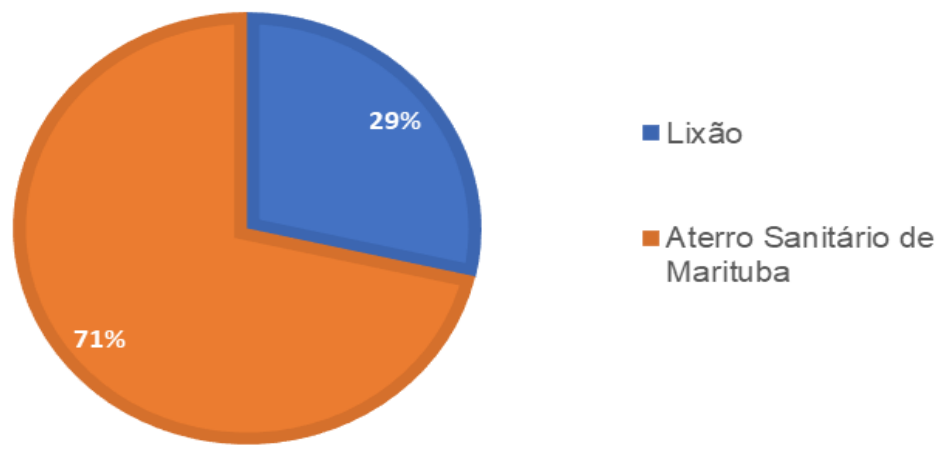

Figura 4: Afirmação dos entrevistados sobre o destino dos resíduos em Belém.

Fonte: Os autores (2020).

Foi questionado aos discentes se 0 aterro sanitário deve receber qualquer tipo de resíduos, porém $88 \%$ das pessoas declararam que a destinação ambientalmente correta das pilhas seriam a logística reversa, ou seja, voltar para a empresa produtora para um destino diferente. De acordo Lima (2020), existe uma grande preocupação por haver certos minerais que são essenciais à saúde humana, mas se em excesso podem causar sérios danos a nossa saúde, isso ocorre com alguns minerais que têm efeito acumulativo nos organismos vivos e por isso vão passando para outros organismos conforme a ordem da cadeia alimentar, visto que quando jogadas em qualquer local, podem ser danosas ao meio ambiente e, em consequência, aos seres humanos. 
Os Resíduos Sólidos Urbanos, também denominado por lixo, são descartados pela sociedade e geralmente tem os seguintes destinos:

a) os lixões;

b) os aterros sanitários; e

c) as usinas de compostagem.

Segundo Dos Santos Garcia (2016), os lixões, são terrenos desocupados, em geral situados na periferia das cidades, onde o lixo é colocado, a céu aberto, sem qualquer tratamento prévio. Sendo um grande promovedor e multiplicador de insetos, ratos, mosquitos, urubus etc. e, que muitas das vezes, são agentes proliferadores de doenças. Com efeito, a população extremamente pobre, inclusive crianças, frequentadores estes locais a fim de manter sua sobrevivência, dessa forma, expondo-se a altas taxas de contaminação e doenças.

Os aterros sanitários são lugares apropriados e definidos para depósitos, onde as empresas de coletas depositam o lixo urbano, sobre o qual depois de sua compactação, é coberto por terra para que não fique exposto. Trata-se da disposição mais adequada para a percepção dos resíduos sólidos urbanos.

Entre os discentes entrevistados, $73 \%$ afirmaram que o lixo hospitalar deve ter outro destino, pois são produzidos em unidades de saúde, constituídos de lixo comum, resíduos infectantes ou de risco biológico (sangue, gaze, curativos, agulhas etc.) e resíduos especiais (químicos, farmacêuticos e radioativos) (BORELI, 2018). Ressalta-se que nenhum dos entrevistados afirmou que qualquer resíduo deve ser descartado no aterro sanitário (Figura 5). De acordo com o autor citado anteriormente, a adoção de usinas de reciclagem e compostagem para tratamento e destino do lixo urbano e a dúvida sobre a periculosidade dos resíduos hospitalares, levaram à implementação de sistemas diferenciados específicos para sua coleta em diversos municípios e a utilização de outro destino para eles.

\section{Em sua opnião o aterro sanitário deve receber todo o tipo de resíduos?}

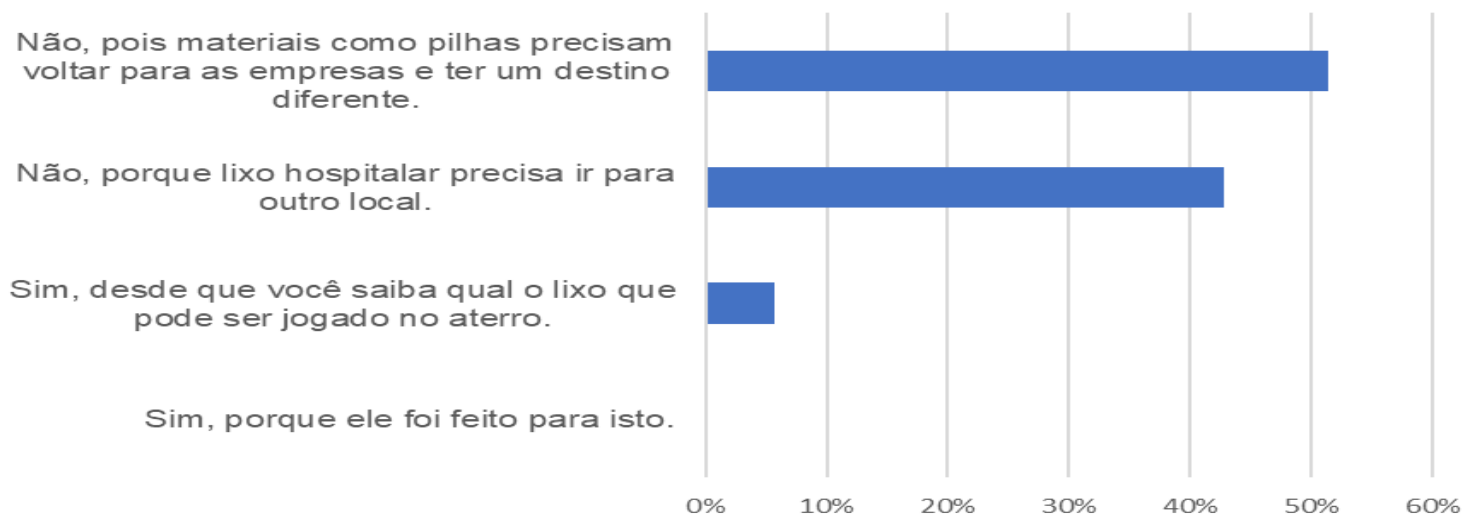

Figura 5: Porcentagem da opinião sobre a destinação dos resíduos.

Fonte: Os autores (2020). 


\section{Conscientização e Educação Ambiental}

Segundo Almeida et al. (2019), atualmente, as atividades humanas têm intensificado a atenção à proteção do meio ambiente, na perspectiva de obter os recursos necessários para a produção de bens e serviços, as atividades humanas têm gerado a crença de que a natureza existe para servir ao homem, ocasionando graves problemas de degradação ambiental, danos aos recursos naturais, às condições de vida e a toda a vida futura no planeta.

Há diversas definições para definir a Educação Ambiental, porém define-se no geral que o objetivo é definir a relação do homem com a natureza de modo a levar à conscientização do homem-natureza para conduzir a uma conscientização do homem da necessidade de autopreservação. Segundo a lei 9.795/99 define:

Art. 10 "Entende-se por Educação Ambiental os processos por meio dos quais o indivíduo e a coletividade constroem valores sociais, conhecimentos, habilidades, atitudes e competências voltadas para a conservação do meio ambiente, bem de uso comum do povo, essencial à sadia qualidade de vida e sua sustentabilidade."

A Educação Ambiental aponta propostas centradas na conscientização, mudança de comportamento, desenvolvimento de competências, capacidade de avaliação e participação dos educandos (REIGOTA, 2017). Assim, segundo Monteiro (2020), também leva o aumento de conhecimentos e mudança de valores, condições básicas para estimular maior integração e harmonia dos indivíduos com o meio ambiente.

Os conflitos socioambientais existem devido as diferentes formas de entendimento em relação ao meio natural, ou seja, as pessoas agem conforme a sua ideia sobre o ambiente. Se apresentam uma consciência ecológica, entendem que o ambiente é o local de habitação de outras espécies, e nos fornece serviços ecossistêmicos e entendendo-se como parte da biodiversidade. Tal compreensão demonstra respeito a natureza e ameniza impactos ambientais (ALMEIDA et al., 2017). Dessa forma, para que se fale em conservação ambiental tem de falar-se em diminuição dos conflitos socioambientais e consequentemente do aumento da Educação Ambiental.

Dos discentes que cursam engenharia ambiental, apenas $42 \%$ responderam saber qual o destino dos resíduos sólidos urbanos na Região Metropolitana de Belém, como mostra a Figura 6. Tais resultados mostram que apesar de terem acesso a informações, os universitários não demonstraram tal conhecimento básico. Isso demonstra um indicativo das deficiências observadas no sistema educacional e falta de conhecimento ambiental da sociedade. Diante do conhecimento dessas falhas pode-se interferir nas práticas de conscientização ambiental enfatizando as principais deficiências. 


\section{ALUNOS DE ENGENHARIA AMBIENTALQUE SABEM A DESTINAÇÃO DOS RESÍDUOS}

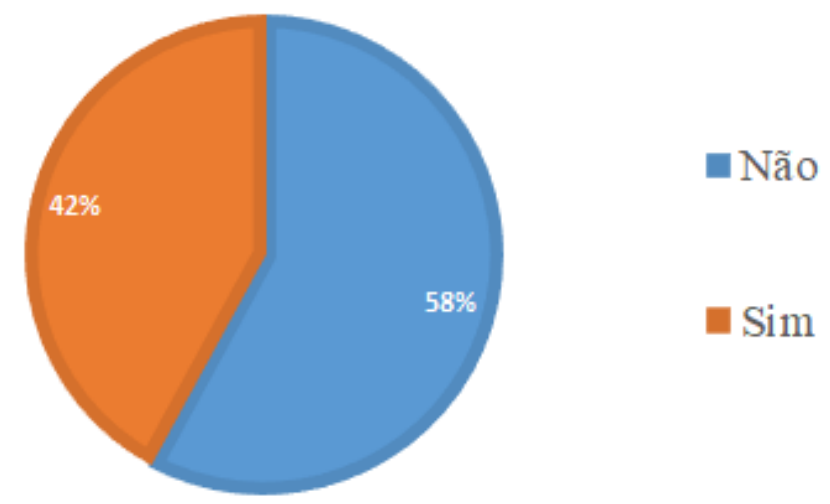

Figura 6: Porcentagem da opinião sobre a destinação dos resíduos.

Fonte: Os autores (2020).

O papel do engenheiro ambiental é contribuir para a melhoria da qualidade ambiental e do desenvolvimento sustentável na sociedade. Sua atuação se dá por meio de práticas que visam a prevenção e a preservação, como proteger e minimizar problemas relacionados à degradação do meio ambiente, elaborar projetos, educar e sensibilizar a população, colocando em prática todo o conhecimento adquirido academicamente. Dessa forma, o engenheiro ambiental é um dos responsáveis pelo importante busca da qualidade ambiental, abordando assim temas que façam com que a conscientização exerça um grande papel na sociedade. Portanto, tal resultado demostra a falta de conhecimento básico sobre destinação dos resíduos, sendo uma informação importante para a contribuição da profissão.

Segundo Almeida et al. (2017), estimular a percepção ambiental quanto aos impactos socioambientais consequentes é, em tal situação, uma tarefa primordial e primária para despertar a sensibilização individual e estimular a conscientização. Assim, para atingir o objetivo da mudança de paradigmas e concretização da conscientização, faz-se necessário, que o conhecimento se transforme em atitude e em seguida em mudança da conduta individual e posteriormente na coletiva. Por meio da Educação Ambiental busca-se trazer a conscientização sobre a situação atual do meio ambiente, demonstrando que que o homem é uma parte da natureza e não superior a ela.

Dessa forma, a implantação da Educação Ambiental através de informações constantes, eventos, campanhas que chamem a atenção da população e informem, criando tais condições para garantir o envolvimento e visando melhorar a qualidade dos indivíduos, orientar o uso e descarte dos resíduos e serviços que a natureza oferece. Também tem como objetivo modificar de forma significativa o modo de agir, pensar de forma individual e coletiva para o desenvolvimento ecológico. 


\section{Conclusões}

As decisões que envolvem a gestão de resíduos sólidos urbanos são, fundamentalmente, decisões de saúde pública e, portanto, precisam estar integradas às políticas econômicas, sociais e ambientais. Contudo, a reciclagem na RMB contribui significativamente para a sustentabilidade, impacto social e qualidade de vida. Dessa forma, a sustentabilidade é a busca do equilíbrio entre o ser humano e a natureza, portanto, precisamos adotar estilos de vida diferentes e caminhos de desenvolvimento que respeitem os limites naturais.

Através da revisão literária percebeu-se que o descarte inadequado do resíduo sólido urbano pode causar consequências para o meio ambiente e para a saúde humana. Portanto, é um problema socioeconômico, ou seja, vários indivíduos são afetados pelo descarte inadequado do resíduo nas cidades, que causam proliferação de insetos, transmissão de doenças, poluição visual, entupimento de bueiros, entre outros.

Os resultados foram relevantes, já que apresentam as principais dificuldades da população acadêmica com relação a destinação correta dos resíduos; a necessidade de mudanças de hábito para separação dos materiais com potencial reciclável e; a falta de conhecimento sobre os resíduos gerados na Região Metropolitana de Belém. Um fato que chama a atenção é o desconhecimento dos universitários de engenharia ambiental sobre o destino dos resíduos sólidos, demonstrando a necessidade de muito envolvimento institucional, no tocante à Educação Ambiental, pois o objetivo principal desses futuros profissionais é a sua inserção na sociedade, como parte integrante e ao mesmo tempo atuante, nas relações entre sociedade e ambiente.

Observa-se que muito deve ser feito em relação ao destino dos resíduos. Percebe-se a necessidade de maiores informações e conscientização, pois a coleta seletiva é o passo mais importante para que os vários tipos de resíduos tenham uma destinação ambientalmente correta. Uma forma eficiente de tomada de consciência dos cuidados que devemos ter com o ambiente, primeiramente é se enxergar como parte integrante do meio, ou seja, do ambiente físico e social, para depois dar o devido olhar de importância ao meio ambiente e assim desenvolver práticas sustentáveis dentro da sociedade.

\section{Agradecimentos}

Ao Programa Institucional de Bolsas de Extensão - PIBEX, pelo apoio financeiro à pesquisa; à Universidade Federal Rural da Amazônia. 


\section{Referências}

ALMEIDA, N.C.C. et al. Educação Ambiental: a conscientização sobre o destino de resíduos sólidos, o desperdício de água e o de alimentos no município de Cametá/PA. Revista Brasileira de Estudos Pedagógicos, v. 100, n. 255, p. 481-500, 2019. [Link]

ALMEIDA, R.; SCATENA, L.; LUZ, M.S. Percepção ambiental e políticas públicas-dicotomia e desafios no desenvolvimento da cultura de sustentabilidade. Ambiente \& Sociedade, v. 20, n. 1, p. 43-64, 2017. [Link]

BARBIERI, J.C. Gestão ambiental empresarial. Saraiva Educação SA, 2017. [Link]

BORELI, D. Gestão de resíduos sólidos infectantes em uma unidade hospitalar. Nucleus, v. 15, n. 1, 2018. [Link]

BRASIL - SNIS, Secretaria Nacional de Saneamento Ambiental. Diagnóstico do Manejo de Resíduos Sólidos Urbanos - 2018.

BRASIL. Decreto no 5.940, de 25 de outubro de 2006. Institui a separação dos resíduos recicláveis descartados. Disponível em: < http://www.planalto.gov.br/ccivil 03/ ato2004-2006/2006/decreto/d5940.htm>

Acesso em: 30 dez. 2020.

BRASIL. Lei 9.795, de 27 de abril de 1999. Dispõe sobre a Educação Ambiental. Disponível em: < http://www.planalto.gov.br/ccivil 03/leis/19795.htm> Acesso em: 30 dez. 2020.

BRASIL. Lei no 12.305, de 2 de agosto de 2010. Institui a Política Nacional de Resíduos Sólidos. Disponível em: http://www.planalto.gov.br/ccivil 03/ ato2007-2010/2010/lei/l12305.htm> Acesso em: 30 dez. 2020.

CORREIA, R.N. et al. Diagnóstico preliminar da cadeia de reciclagem do alumínio na área urbana de Humaitá - AM. Educamazônia - Educação, Sociedade e Meio Ambiente, v. 20, n. 1, Jan - Jun, p. 186-196, 2018.

DE CARVALHO, M.R.B. et al. Logística reversa e coleta seletiva do lixo: A Educação Ambiental como ferramenta auxiliar no processo de reciclagem do lixo eletrônico. 2016. Tese de Doutorado. Universidade Federal do Pará.

DE SOUZA, Z.H.; MOURA, V.S.F.; MACHADO, B.L. Composição gravimétrica dos resíduos sólidos domiciliares dispostos no lixão do município de Mineiros Goiás. Brazilian Journal of Development, v. 6, n. 5, p. 31392-31401, 2020.

DOS SANTOS GARCIA, Marcio Barreto et al. Resíduos sólidos: responsabilidade compartilhada. Semioses, v. 9, n. 2, p. 77-91, 2016.

GONÇALVES, P. A cultura do supérfluo: lixo e desperdício na sociedade de consumo. Editora Garamond, 2018. 
INSTITUTO BRASILEIRO DE GEOGRAFIA E ESTATÍSTICA. (2010). Censo Demográfico de 2010. Rio de Janeiro: IBGE. Disponível em: $<$ https://www.ibge.gov.br/estatisticas>

LIMA, L.M.J.A. et al. Análise do descarte de pilhas e baterias: um estudo de caso na Universidade Federal Rural da Amazônia, Belém-PA. 2020.

MARQUES, E.A.F. et al. Gestão da coleta seletiva de resíduos sólidos no Campus Pampulha da UFMG: desafios e impactos sociais. Revista de Gestão Ambiental e Sustentabilidade, v. 6, n. 3, p. 131-149, 2017.

MOL, M.P.G.; QUEIROZ, J.T.M.; GOMES; J.; HELLER, L. Gestão adequada de resíduos sólidos como fator de proteção na ocorrência da dengue. Revista Panam Salud Publica. 2020.

MOLINARI, D.R. Entre o luxo e o lixo: desafios da sociedade de consumo na gestão dos resíduos sólidos. 2017.

MONTEIRO, A.R. Educação Ambiental: um itinerário para a preservação do meio ambiente e a qualidade de vida nas cidades. Revista de Direito da Cidade, v. 12, n. 1, p. 830-850, 2020.

REIGOTA, M. O que é Educação Ambiental. Brasiliense, 2017.

RODRIGUES, N.C. O descarte inadequado de resíduos na orla do Lago Paranoá: a necessidade de uma Educação Ambiental crítica. 2017.

SANTOS, C.R. et al. Reciclagem de papel e o desenvolvimento de ações sustentáveis: uma parceria entre o PIBID interdicisplinar em Educação Ambiental e a Com-Vida escolar. Revista Brasileira de Educação Ambiental (RevBEA), v. 12, n. 2, p. 114-126, 2017.

SOARES, F. R.; MIYAMARU, E.S.; MARTINS, G. Desempenho ambiental da destinação e do tratamento de resíduos sólidos urbanos com reaproveitamento energético por meio da avaliação do ciclo de vida na Central de Tratamento de Resíduos-Caieiras. Engenharia Sanitária e Ambiental, v. 22, n. 5, p. 9931003, 2017.

SOUZA, G.S. et al. Educação Ambiental como ferramenta para o manejo de resíduos sólidos no cotidiano escolar. Revista Brasileira de Educação Ambiental, v. 8, n. 2, p. 118-130, 2014. 